\title{
M\&E and Budget Program Performance Measurement in Ukraine: Current State and Needs for Improvement ${ }^{\#}$
}

\author{
Sergii SLUKHAI
}

As Ukraine gained independence, its national budget system was designed. However, the traditional public expenditure management methods (such as institution-based budgeting) inherited from the Soviet past quickly came to contradiction with turbulent economic and social reality which demanded a much more effective and flexible usage of scarce public funds. The soviet-type paternalistic state became a hostage of securing high social expectations which were not supported by sufficient resources, which ended in public finance collapse and hyperinflation in the beginning of the 1990s. It became clear that persisting methods of public expenditure management were inadequate. There was a great need of finding the right linkage between public needs and the resources available, as well as creating motivation for public administrators to manage these resources with better outcomes.

Ukraine has made definite steps towards implementing core elements of performance-based budgeting (PBB) to managing public expenditures since 1998, when major spending units $(\mathrm{MSU})^{1}$ at the national level became for the first time obliged to submit their budget requests complemented with basic goals to be achieved within this year. Some elements of the modern monitoring and evaluation (M\&E) system were also introduced. These steps were undertaken basing on wide-spread perceptions concerning M\&E importance: $M \& E$ should assist the public bodies and society in identifying whether goals, objectives and specific

\# This article is processed in course of the implementation of the project Development of Monitoring and Evaluation System for Program-Based Budgeting Methodology carried out by Ernst \& Young LLC for the Ukrainian Ministry of Finance (2010-2011). Dr. Sergii Slukhai - Professor; Economics Faculty, Taras Shevchenko Kyiv National University, 90a Vassylkivska Street, Kyiv 02033, Ukraine; <serg1955@ meta.ua>.

1 According to Ukrainian legislation, major spending units are the separate national public bodies of different status (ministries, state committees, public agencies etc.) which are assigned to receive allocations from the state budget as set by the Annual Budget Law. 
performance indicators (PIs) have been achieved; it should serve as an effective tool for motivating implementers towards reaching the maximum possible level of fulfilment of the goals within existing funding limits. M\&E would allow to operationally generate, obtain, and use complete and reliable information on achieving PIs, determine the reasons of their deviation from the planned values which could (if necessary) be used for modifications in the scale and scope of implementers' activities. It could also enable evaluation of short-term and long-term social and economic benefits obtained by the public due to successful realization of each separate budget program (BP).

The core element of M\&E activities is setting PIs whose values serve as a yardstick for measuring program's success. In order to serve the goal of monitoring and assessing the program performance, they should have the following desirable features: be relevant, bounded (not too extensive in number), clear, understandable, valid, reliable, timely, comparable, comprehensive, and reasonably within the control of those who are made accountable for their achievement (Jackson, 1995).

It is known that the best $\mathrm{M} \& \mathrm{E}$ practices are primarily inherent to international organizations and nongovernmental (non-profit) organizations. Their experience is generalized in some manuals and guides which are recommended especially for utilization in developing and transition countries (Kusek - Rist, 2001; Mackay, 2007; OECD, 1998; OECD, 2008; Robinson - Last, 2009; World Bank, 2004). However, individual countries tend to be selective in implementing the elements of $\mathrm{M} \& \mathrm{E}$, combining both universal and specific features, have achieved positive outcomes while introducing the modern M\&E toolkit.

The process of shifting to PBB in Ukraine was pushed up by the adoption of the Budget Code (2001), both on the national and local levels, and of the Concept of Program-Based Budgeting in the Budget Process (2002). MSUs' responsibilities within the budget process were clarified i.e. they became responsible for compiling budget requests, approving passports of budget programs (BP), and reporting on their execution; BPbased public expenditure classifications were enacted, etc. Since monitoring and evaluation are the core elements of PBB, some regulations concerning establishing a system to trace progress in $\mathrm{BP}$ realization, were enacted. External monitoring was vested on the Ministry of Finance (MoF), the Accounting Chamber, and the State Supervision 
and Control Service (KRU). The basic functions of BP internal monitoring were vested on MSU.

Nevertheless, as many Ukrainian public sector researchers showed (Sanzharovskyi - Polianski, 2007; Heyets, 2008; Tertychka, 2002a; Tertychka, 2002b), there is still a lack of a unified approach to carrying out $\mathrm{M} \& \mathrm{E}$ and using its results for improving $\mathrm{BP}$ implementation, i.e. there is lack of instruments in tracking progress, or in evaluating the economic impact of public spending on specific BPs in view of national strategic goals. In addition, the information widely spread by Ukrainian media along with current legal prosecution of the top officials of a previous government (in some cases connected with non-targeted usage of public moneys), suggests that in practice there is a number of flaws in current $\mathrm{M} \& \mathrm{E}$ procedures, which make possible unsatisfactory state budget execution, as well as weak accountability of public institutions. Therefore, the current M\&E system as part of PBB in Ukraine requires considerable updates and refinements, while its key elements should be reviewed and modernized.

Having as a background some recent positive developments in M\&E sphere, the research questions of this paper could be set as follows: (i) to what extent a sufficient base for an effective $M \& E$ of public expenditure programs in Ukraine is provided; (ii) how the M\&E activities are carried out in practice; (iii) what could be done in order to make public sector $M \& E$ in Ukraine more efficient.

\section{M\&E institutionalization}

There is no unified legal act in Ukraine covering PBB and, respectively, $M \& E$ in the public sector, unlike in many other countries. It is worth mentioning e.g. the Government Performance and Results Act (GPRA), adopted in the USA in 1993, which was a landmark event in the history of administrative reform in this country and in the world. According to GPRA, governmental agencies were required to submit five-year strategic plans with measurable goals and performance targets; these plans were to be updated every three years; annual performance reports were to be submitted to the Congress; reports were to show threeyear comparative data for PIs, etc.

In Ukraine, the legal basis of PBB is made of a number of legal acts and bylaws issued by the Cabinet of Ministers (CMU), Ministry of 
Finance $(\mathrm{MoF})$, and other authorized bodies (first of all the KRU). The most general act in this field is the Budget Code, first adopted in 2001 and then significantly revised in 2010 . The Budget Code as of 2001 set the norms regulating implementation of audit and financial control: they should be carried out at all stages of the budget process, providing, among other things, for evaluation of operations and compliance of results thereof with the established tasks and plans. The MSUs were supposed to bear responsibility for the organization and maintenance of internal financial control and audit. External control and audit of financial and economic activities, as well as analysis of budget funds utilization effectiveness shall be carried out by the Accounting Chamber and by KRU. MoF is assigned the responsibility of controlling the compliance of budget procedures on all stages with the budget legislation, which referred to BPs as well. It is worth mentioning that the first Budget Code version reflected obsolete "procedural" approach to accountability and budget management; so that it did not even refer to "monitoring" (operating instead with terms like "control") and "evaluation" ("audit" instead). Further developments in public management towards PBB demanded respective changes in legislation which were enacted in 2010.

The current version of the Budget Code (2010) operates with more advanced instruments and directly assigned responsibility for performing budget program evaluation and monitoring to MSUs. This evaluation must be based on PIs as presented in BP documentation. The results of $\mathrm{BP}$ evaluation could be used for changing budget appropriations in the ongoing and sequential years. MoF also became responsible for elaboration of PIs in different fields of public bodies' activity.

The most important subject to be monitored and evaluated (audited) since the PBB approach was adopted, has been the budget program. The main document basing on which $M \& E$ is to be carried out, is its passport. This passport should contain amounts of money assigned to a BP in a respective year and PI values to be reached. The PIs are divided into four groups $^{2}$ :

- "costs" (the scope and structure of resources which are provided for the BP, and the cost structure);

2 The exact description of PIs is provided by the MoF in its Order \# 1252 as of 27.10.2009 "On Performance Indicators of Budget Programs". 
- "product" (scale and scope of products manufactured, services rendered or works performed, number of consumers of goods, works, services, etc.);

- "effectiveness" measures like consumption of resources per unit of product (cost-effectiveness), relation between the quantity of the goods produced (services rendered, works performed) and the amount of resources allocated (productivity), reaching the objectives (performance);

- "quality" (the resulting quality of the delivered product that satisfies the clients and reflects the declining negative or the growing positive trends in rendering services/goods as a result of funds spent on BP).

Trying to understand the general situation with M\&E, we have to start with BP assessment. According to legislation, BP assessment in Ukraine has to be performed at the planning stage of the budget process. The most important actors here are MSUs and branch departments of the MoF which review their funding requests and $\mathrm{BP}$ documentation. At this stage, the core problem is that only amounts of funding are reviewed, while PIs and their values are not assessed. The reason behind is the following: PIs and their values are submitted and calculated only after the finalization of the budget planning stage, after fixing amounts of appropriations to each specific BP. In result, the most PIs are usually not justified for the objective of performance evaluation and their values are not validated.

Our study of some BPs showed that the authorized budget process participants concentrate during the BP implementation stage mainly on monitoring rather than evaluation activities. Currently, only three out of five elements of the program cycle are subject to effective $M \& E$ procedures, namely: available resources, activities and products, which, in fact, are of short-term nature. The elements that are of medium- and longterm nature (effects and influences, their stability etc.), as a rule, do not undergo significant detailed analysis from BP implementer side and respective controlling authorities (MoF, KRU, and the like). At the same time, it must be noted that MSUs (and BP implementers) do not have special operational units or a corresponding administrative system to coordinate M\&E activities. MSUs do not perform internal evaluation. Moreover, it seems that they are not really interested in performing it because the main form of such an "evaluation" is an internal financial audit aiming to check the purpose-related money spending and procedural legal compliance. 
Generally, action plans of M\&E activities were not even compiled, and no funding was reserved in the BP cost estimate for monitoring or evaluation activities. Thus, monitoring is carried out mostly basing on tracing the achievement of planned financial indicators (money spending) and product indicators, while tracking of other data of BP passports is considered mostly a formality. As a rule, no independent experts are appointed in the evaluation.

All these could be reasons why the practice of controlling the achievement of the BP planned indicators and purpose-related usage of public funds currently dominates the sphere of M\&E. These issues were most often scrutinized in course of audits performed by the KRU.

As concerns the MoF, it monitors BP implementation on a quarterly and annual basis. But the reviewing process produces poorly informative results because it also concentrates mainly on legality and purposereliance of money spending, thus duplicating functions of the KRU.

MSU's reporting on BP passport implementation to the MoF can be considered as a form of regular monitoring. But the problems that could immediately be identified are whether the actual PIs are really relevant for the purpose of comprehensive BP evaluation. The reason for raising such a question stems from the mere fact that PIs as defined above basically describe costs and products, but not outcomes and impact.

The M\&E performance in Ukraine's public sector is interrelated with general PBB implementation issues. So, it is worth discussing the core element of PBB - explicit formulation of public goals and readiness of the government to link the scarce resources to the level of goals achievement.

Formally, there are strategic goals which are presented in annual, medium-term and strategic governmental programs. But the problem is that these documents are too politicized and thus very vulnerable to political turbulence, which has been very characteristic for Ukraine in 2000s. As concerns national strategy, the document for 15 years (adopted in 2006) was not intended to be passed by the Parliament and remained only a booklet to be presented to international organizations without big implications for BPs' priority setting. 
This creates a situation when goals and objectives of different BPs can not be linked to national priorities, and respective PIs might be vaguely defined - the latter fact corresponds to the well-known political vulnerability of setting clearly-defined and measurable indicators. Thus, there is no big need to assess BPs and evaluate their performance. This undermines the desire to implement and operate an effective M\&E system as a crucial PBB element.

The problems are also aggravated by an overall institutional weakness of the public administration system. The public administration is at the moment beyond the reach of parliamentary control. MPs, in turn, under absence of political competition, do not feel they need to care much about promises given to the voters. So, individual officials seek their position in order to get a grip of free budget funding for their directly or indirectly controlled own businesses or exploit it for their own benefit. Under conditions where the society is being alienated from the formulation of policy priorities and is deprived of information on performance of publicly appointed officials, the situation with M\&E could hardly be changed despite the modest steps undertaken.

\section{Budget program external evaluation}

$\mathrm{BP}$ evaluation is performed by a variety of actors. As concerns CMU and MoF, they mostly limit themselves to checking whether BP progress reports were submitted on time and whether the amounts of money were duly spent. "Evaluation" in the strict meaning of the word is being performed by the KRU in the form of a so called "effectiveness audit". Its formal definition sounds so: "state financial control directed at securing effectiveness of public fund usage as concerns realization of the planned goals and finding inhibiting parameters". Such definition differs significantly from classical notion of audit which assumes a control function over quality of managerial activity; evaluation, in contrast, is control of program functioning (Kuzmin - O'Sallivan - Kosheleva, 2009). Basically, the real content of "effectiveness audit" goes far beyond "audit" concept, being essentially very close to "program evaluation".

According to the CMU Resolution \#1017, the main tasks of effectiveness audits performed by the KRU are as follows:

- evaluation of BP result compliance with PIs; evaluation of effectiveness of BP execution; 
- detection of blunders and flaws of organizational, normative, legislative, and financial character that hamper the timely, full and duly implementation of the planned objectives;

- establishment of the level of impact that detected blunders and flaws have on the realization of the planned goal;

- elaboration of proposals regarding the methods (forms and approaches) of increasing the effectiveness of budget fund usage.

The Resolution defines also main instruments that should be utilized when carrying out the effectiveness audit, e.g.:

- analysis of regulations, calculations and feasibility assessments, methodology employed, enactments and publications regarding the activity within a BP which undergoes the effectiveness audit;

- the results of previous controlling activities;

- parameters of statistical, financial and operating reporting;

- comparison of data on actually achieved PIs with the planned parameters in dynamics for several years, and with the nationwide and foreign experience in the particular field of activities, etc.

The respective audit reports must be submitted to MSU for taking measures to raise the BP effectiveness, as well as to other governmental bodies.

There are some weak points in this "effectiveness audit" approach, namely vagueness in criteria of BP appraisal. According to the KRU Order "On Improving the Audit of Budget Program Effectiveness" (\# 444 as of $15^{\text {th }}$ December, 2005), BP effectiveness evaluation should be carried out using the following scale:

- "efficient", in case the PI values exceed or equal expected ones related to the level of funding;

- "sub-efficient", in case the level of PIs is slightly below the one expected for the granted amount of funding;

- "inefficient" if the level of PIs is significantly lower than expected in relation to assigned funding.

Such an evaluation scale generates the following reasonable questions: (i) how to approach the aggregation of PI values in order to see whether the overall performance is "efficient" or not; (ii) to which extent the PI aggregate value may deviate from the "appropriate" level, in order 
to be judged as "efficient"; (iii) how to define appropriateness of observed ratio between amount of funding and overall PI levels? These questions remained unanswered, and this leads us to assume that many possibilities for subjectivity in BP evaluation are present.

Despite the effectiveness audits are not intended to be used for charging budget offence against MSU administrators, our interviews with their representatives reveal that the KRU's effectiveness audits actually are not yet perceived by them as a useful tool aimed at improving BP effectiveness. Nowadays, there are many examples when KRU's audit findings were used not for finding ways of BP improvement, but for billing criminal offence against some implementers and highest state officials. That is why realization of recommendations produced in the course of effectiveness audits remains a big issue: in most cases MSUs do not approach these recommendations seriously enough, on grounds that "they themselves know better how to run the BP". Their reaction to audit reports could be rather offensive - frequently ranging from a letter of disagreement with findings followed by a long-lasting exchange of messages, to silent ignoring. There are no mechanisms which could induce MSUs to adequately react to those findings.

Carrying out effectiveness audits at BP implementers' demand is hardly practiced. Since 2005, only individual cases of the practice have been recorded, namely when new heads of ministries/departments were appointed because they showed true interest in knowing the real situation within their bureaus.

Basically, the BP effectiveness audit is initiated by the KRU basing on its economic/social importance and on the amount of public funding allocated. In addition, selection of the subject of audit depends on the requests of other public bodies like the Accounting Chamber, the State Tax Administration, the Customs Office, the State Treasury etc. With KRU's current staffing and abundant BP number the effectiveness audit could not be all-encompassing.

The current register of BPs holds about 1000 items, so it is not physically feasible for the KRU to audit all running BPs within a budget year. As a rule, only a minor part of them undergoes this procedure. For example, in 2008 the KRU held 18 effectiveness audits, in the course of which the effectiveness of 63 BPs was studied; in 2009, 14 effectiveness audits covered 54 BPs. 
Given the current structure, the number of professional personnel of the service allows to hold the audit of one BP once in every 15 years. In the case of annual evaluation, it is necessary to increase the number of personnel or to outsource independent experts more often. Presently, the $\mathrm{KRU}$ is unable to pay labour compensation to such experts, hence they are outsourced free of charge. In case of a radical decrease in the number of BPs in the future, the current KRU staffing might be sufficient for executing effectiveness audits of all BPs.

Since the KRU's limited staff capacity is related to the amount of work required to have all BPs evaluated, the issue of BP scale and scope should be mentioned here because their overabundance and weak compliance to the PBB concept create significant problems for M\&E performance.

There is no official classification of BPs in Ukraine. From an M\&E prospective, it would be useful to distinguish BPs by functional criteria:

- BPs related to the realization of government policy within the framework of the state mid- and long-term special purpose programs (they should be considered as "permanent" BPs);

- BPs related to the financial support of governmental policy (e.g. transfer of funds to international organizations etc.);

- BPs related to administrative functions.

All three types have been presented in the respective annual budget allocations; usually, the MSUs run all three different types of BPs simultaneously, which goes not well enough in line with PBB concept, because specific functions assigned to MSU are split among several different programs, thus, also monitored and evaluated separately. We suppose that expanding the budgeting time horizon to mid-term planning provided in the current version of Budget Code (2010) would require also merging these three BP types within the "permanent" BP framework.

As for now, the majority of BPs belongs to the second and third groups to which approximately 90 per cent of budgetary allocations have been assigned.

There is no explicit distinction in M\&E procedures as concerns the BP of above-mentioned groups. But obviously, the functional specificity of $\mathrm{BP}$ requires differing approaches to M\&E. Taking this into account, 
most complex are BPs in the first group determining the prospective development of the national economy and society in general. The problem with this group is $\mathrm{BP}$ average scale.

Vast majority of BPs related to the first group operate on a very small scale (with amounts less than UAH million 20); they accounted for less than 10 per cent of budget expenditures; the average scale of a BP dedicated to governmental policy implementation barely reaches UAH million 10 .

The problem is also that the small scale of a BP makes it almost impossible to measure their public impact and sustainability. That is the reason why the overseeing authorities opt for the simplest traditional (soviet-type) approach to evaluation - checking legality and purposereliance of public moneys spent without deeper investigation.

Weak public involvement in M\&E of the activities of executive bodies responsible for BP implementation is a common issue for Ukraine. The information about progress in BP implementation is usually not made publicly available, and the beneficiary's influence on the formation and improvement of BPs is very modest or even negligible. Only recently, in 2010, a legal requirement to publicize the annual BP implementation results has been enacted.

\section{Some evidence from practice of objective formulation and performance measurement for the public sector}

Certain peculiarities of the Ukrainian approach to BP documentation make $M \& E$ quite problematic. Among these - obsolete forms/templates of main documents related to BP which prevent them from being utilized as effective instruments of M\&E. BP passports include PIs which very often have no linkage to the BP goal and objectives.

PIs are sometimes selected in a way that does not allow measuring them directly because of absence of relevant statistical information. Moreover, they may have no deep connection to the groups they are intended for (costs, product, effectiveness, quality). The last group of PIs - quality - is the most controversial one because it cannot be objectively assessed; so generally the relevance of using it in M\&E is doubtful. This could be a reason for the absence of systematic evaluation of the goals and objectives of a specific BP and of analyzing the main factors which 
may have an impact on program realization. Despite of the fact that MSUs are obliged to submit (along with their periodical progress reports) detailed explanation on why PI values deviate from the set ones, they usually do not do it.

Our analysis of documentation of the two largest (up to UAH 10 billion annual spending each) BPs dedicated to (i) motor road maintenance and construction and (ii) coal mining industry support has fully proven this constellation.

\section{Budget program dedicated to motor road maintenance and construction}

According to its passport, this BP has a goal to secure stable functioning and development of the road net of general usage. To reach this goal, the following objectives have been set: (1) formulation of the public policy as concerns motor road construction; (2) design and implementation of the state programs dedicated to development of the transport corridors, secure road traffic, improvement and development of the road facilities; (3) organization of construction, reconstruction, renovation and maintenance of the motor roads, of respective engineering and service facilities; (4) technical renewing of the road facilities.

The following critiques could be appropriate while assessing these objectives:

- Concerning objective \#1. Formulation of the state policy in the field of motor road construction could hardly be considered as an objective of any BP because MSU (as a BP implementer) has to implement some public policy adopted by the state and cannot develop any public policy for itself. As concerns PIs, none represents this objective.

- Concerning objective \#2. It looks like design and implementation of the state programs could not be included to the BP objectives because these ones have to belong to the domain of administrative bodies. Relating its objective meaning, this objective could be split at least into three separate ones (development of transport corridors, getting higher security of road traffic, enhancing current road facilities). These three real objectives are presented by two PIs (related to lessening number of traffic accidents) in the BP documentation. 
- Concerning objective \#3. Basically, its formulation looks inadequate because BP itself cannot "organize" anything. However, this objective is closely linked to the $\mathrm{BP}$ goal and is represented in respective PIs.

- Concerning objective \#4. This objective is well enough related to the BP goal, but it is presented in only two PIs which looks not sufficient.

One could state that all the objectives' formulations have significant flaws which respectively are reflected in PIs. More over, not all of them are connected to any measurable indicators. It would be desired to amend the objectives' formulations and redesign the list of respective PIs.

As concerns PIs, they are divided into four groups as prescribed by respective BP documentation standards presented above.

First group (costs) is represented by the following three PIs: mileage of motor roads of national importance; mileage of motor roads of local importance; mileage of shares with unfinished construction and reconstruction work. Basically, all three are not relevant for measuring costs having no direct linkage to inputs used in course of $\mathrm{BP}$ implementation.

Second group (product) is presented by seven (!) PIs: launching operation of the motor roads of national importance; launching operation of the motor roads of local importance; mileage of the motor roads of national importance with capital improvement; mileage of the motor roads of local importance with capital improvement; number of applied researches in the field of road maintenance and construction; number of persons receiving course of medical rehabilitation; number of road equipment purchased; number of constructed salt storage facilities.

The last three PIs of this group cannot belong to "product" because they obviously represent inputs for road maintenance and construction; they also are defined in a way that makes them very doubtful even for cost PIs; the first four PIs in this group are not clearly defined and could be aggregated.

The third group (effectiveness) is represented by three PIs: share of capital renovation in total amount of work dedicated to road renovation and maintenance; mileage of the motor roads of national importance 
transferred to higher road category; mileage of the motor roads of local importance transferred to higher road category. Basically speaking, all the three PIs have no relevance to effectiveness as defined by respective standards (relation of inputs and costs to product) and could be considered as PIs for the quality group.

The fourth group (quality) is presented by two PIs: number of sites deregistered as sites of concentrated traffic accidents; diminishing the number of traffic accidents caused by flaws in road maintenance. These two PIs surely belong to quality measures, but they incorporate significant risk of subjective judgment for road police reports concerning what really caused a traffic accident.

Summing up, we could see that PIs as determined in this BP documentation do not follow the MoF guidelines concerning performance indicator definition because most of them even do not match the group they have to. They also are not closely related to the BP goal and objectives. That is why these PIs in total are not suitable to track BP performance and need to be fully reformulated.

\section{Budget program dedicated to coal mining industry support}

According to its passport, this BP has an aim to secure simple-scale reproduction and balancing costs of the loss-making enterprises through selling their produce and receiving budget means which will contribute to the extended-scale reproduction.

Such formulation of the goal is quite vague and too complicated. It does not reflect the most important issues to be solved by the BP (e. g. it does not state which enterprises will receive budget support - any or only public ones; in fact, only public coal mining enterprises are eligible for budget support).

In the BP passport, there is only one objective set - securing timely wage payments for coalminers. Such objective is not linked to the abovementioned goal which requires much broader approach to BP scale and, subsequently, is not represented in PIs.

As concerns PIs of this program, there is no need to discuss them in detail, because they have the same flaws as in case of the previous BP. 
But they also have some distinct features with make them not suitable to measure BP performance.

First, the most PI values here are set as "internal projections" of the respective MSU. This fact itself makes it doubtful, to use them for performance measurement. PIs vales must reflect the actual state of affairs, not the anticipated or projected one.

Second, the cost PIs include only unit cost of the coal and amount of salaries and wages to be paid, so they did not reflect the total spending within the BP.

Third, such indicators like loss margin in coal price and share of state fiscal support per one t of coal extracted do not have much common with effectiveness measurement.

Forth, the quality PIs which are here basically cost indicators; thus they are not appropriate for quality measurement.

The examples of two BPs presented above demonstrate that performance measurement is one of the most problematic issues in M\&E sphere in Ukraine. In order to make PBB an effective means of public expenditure management, the prevailing formal approaches have to be eliminated. It also raises a question of the BP assessment in course of which the flaws shown above can be filtered and corrected.

This all means that real PBB implementation in Ukraine still has a long way to go to allow for a functional approach to managing public funds at the central government level.

\section{Conclusion}

PBB and M\&E as its integral part cannot be considered a panacea for a decisive improvement of public sector budgeting. However, reality is pushing the government to try new approaches proven as more effective for managing scarce resources dedicated to public service delivery, and to demonstrate its efficiency and growing accountability versus societal demands.

In Ukraine, the M\&E system as concerns BPs looks still incomplete: the legal basics regarding $M \& E$ have been introduced, but a rigorous 
approach is still lacking. There is need for a unified legal frame for the whole public sector to regulate its institutional side and unify requirements for $\mathrm{M} \& \mathrm{E}$ implementation. The legislative and normative acts still lack definitions of the essence and tasks of "monitoring" and "evaluation" as concerns BPs and, thus, do not make formal distinctions between them. The current regulatory and legal framework does not allow a full-scale evaluation of BP fulfilment, and thus does not create proper grounds for increasing effectiveness in managing budget funds directed to a specific BP. As a result, effectiveness audit results obtained by the KRU do not permit a comparison of different BPs and respective managerial decisions.

$\mathrm{M} \& \mathrm{E}$ is carried out mainly on the planning phase (assessment of BP concerning its correspondence to the objectives of the state development strategy and funding capacity) and, to some extent, on the implementation phase (tracking BP cost estimate completion by the State Treasury and the MoF). As concerns the effectiveness audit, it is basically an ex-post control which is assumed to evaluate how a BP was performed after the budget year ended, so it has no implications for the ongoing budget process and needs to be performed as an element of medium-term budgeting, not only of short-term (annual) one. The principal M\&E risk under such a system could be associated with evaluation mechanisms where the procedures are formulated, but evaluation criteria are not welldefined, and with an absent possibility to correct BP performance within its implementation stage (especially when it is assigned to support a midterm state special-purpose program), and, finally, with institutional/personal interrelations of "controllers" and the subjects of their activity - MSUs in the first line.

Some drawbacks in the design and implementation of BPs are observable: the linkage between BP goals/objectives and PIs assessing a program's progress, is weak; in many cases, PIs do not fit well for evaluation of BP performance; analysis of PI value deviations is missing; formal approach to BP action plan compilation makes it difficult to control its implementation. Current regulatory and legal framework does not provide effective stimuli for using $\mathrm{M} \& \mathrm{E}$ as a tool for increasing the effectiveness of BP administration.

Activities in evaluation are mostly dedicated to controlling of BPs' spending legality and purpose-reliance. External evaluation is conducted in form of effectiveness audit (performed by the KRU) and covers many 
tasks usually performed in the course of program evaluation. The results of monitoring and effectiveness audits are not fully taken into account in the public decision making process; information resulting from $M \& E$ is not available to the public. KRU's activities in conducting effectiveness audits are not fully effective due to persisting imperfections in BP documentation, lack of qualified staff to carry out such evaluations on an annual basis. Criteria for BP evaluation do not allow for an integral evaluation of program effectiveness, and, in the long run, for decisionmaking with regard to some BPs.

While evaluating certain BPs, a differentiation according to their types (one suggestion could be 'scale') has to be introduced in order use the resources dedicated to auditing more cost-effective with regard to overall effectiveness.

It must be noted that the formal character of $M \& E$ activities is largely preconditioned by the situation with the state finance of Ukraine, permanent budget sequesters and problems with annual state budget approval (in the course of the last several years, it has been approved with severe violations of the Budget Code). Given this, monitoring BP performance is deprived of purpose in the absence of proper funding. At the same time, it preconditions a call for instituting a working M\&E system, raising the issue of reviewing the list of BPs, banning its further extension, and broadening the budget planning horizon.

To make some steps in this direction, the changes in BP legal framework, an improvement of $\mathrm{M} \& \mathrm{E}$ procedures, and better institutionalizing could be suggested. As concerns the MoF, it would be highly desirable to approve a set of recommendations concerning M\&E methodology to be implemented at the MSU level. The role of BP assessment has to be raised significantly in order to avoid situations with wrong performance measurement. There also needs be an approved requirement for each BP to undergo a periodical evaluation procedure with regard to its specifics and nature. MSUs should be pushed to institute a complex monitoring system basing on reliable data sources involving real-time on-line access of the authorized bodies to relevant BP information.

In the long-run, a question of external evaluation of BPs could be raised. Of course, an external evaluation would involve additional expenses. As a benchmark we could consider the five percent recommended for the noncommercial sector (Reed - Morariu, 2010) - but actually an average NPO 
spends significantly less. So an appropriate expense level could be around one percent depending on BP scale and specifics.

\section{References}

[1] Heyets, V. M. (ed.) (2008): State Purpose-Oriented Programs and Regulation of Programming Process in the Budget Sphere. Kyiv, Naukova Dumka, 2008.

[2] Jackson, P. M. (1995): Measures for Success in the Public Sector. London, Public Finance Foundation, 1995.

[3] Kusek, J. Z. - Rist, R. C. (2001): Building a Performance-Based Monitoring and Evaluation System. The Challenges Facing Developing Countries. Evaluation Journal of Australasia, December 2001, Vol. 1 (new series), No. 2, pp. 14-23.

[4] Kuzmin, A. I. - O'Sallivan, R. - Kosheleva, N. A. (eds.) (2009): Program Evaluation: Methodology and Practice. Moscow, PrestoRK, 2009.

[5] Mackay, K. (2007): How to Build M\&E Systems to Support Better Government. Washington, D.C., World Bank, 2007.

[6] OECD (1998): Best Practice Guidelines for Evaluation. PUMA Policy Brief, May 1998, No. 5.

[7] OECD (2008): Performance Budgeting: A User's Guide. OECD Policy Brief, March 2008.

[8] Reed, E. - Morariu, J. (2010): State of Evaluation 2010. Evaluation Practice and Capacity in the Non-Profit Sector. Washington, D.C., Innovation Network, 2010.

[9] Robinson, M. - Last, D. (2009): A Basic Model of PerformanceBased Budgeting. Washington, D.C., IMF, 2009.

[10] Sanzharovskyi, I. - Polianski, Yu. (eds.) (2007): Handbook on Monitoring and Evaluation of Programs for Regional Development. Kyiv, KISS, 2007.

[11] Tertychka, V. (2002a): Governmental Policy: Analysis and Implementation in Ukraine. Kyiv, Osnovy, 2002. 
Slukhai, S.: M\&E and Budget Program Performance Measurement in Ukraine: Current State and Needs for Improvement.

[12] Tertychka, V. (2002b): Issues in Effectiveness and Efficiency Evaluation within Public Policy Analysis. Bulletin of Ukrainian Academy of Public Administration, 2002, No. 1.

[13] World Bank (2004): Monitoring and Evaluation: Some Tools, Methods \& Approaches. Washington, D.C., World Bank, 2004. 


\title{
M\&E and Budget Program Performance Measurement in Ukraine: Current State and Needs for Improvement
}

\author{
Sergii SLUKHAI
}

\begin{abstract}
The key elements of a performance-based budgeting methodology have already become a part of the mechanism for public expenditure management in Ukraine. At the same time, there still remains the issue of linking budget expenditures to specific results achieved by specific budget programs which defines the necessity of applying modern approaches to carrying out M\&E. This study presents an analysis of the current state of $\mathrm{M} \& \mathrm{E}$ in Ukrainian public expenditure program management and offers some solutions which could improve its functioning. The analysis has revealed the absence of rigorous selection of performance indicators to evaluate budget program implementation, a need to better institutionalize the monitoring and evaluation activities through functional differentiation of budget programs and changes in approaches to their assessment.
\end{abstract}

Key words: Performance-based budgeting; Monitoring; Evaluation; Budget program; Major spending unit.

JEL classification: H50. 